\title{
Continued Need for Higher Efficiency Photovoltaics
}

\author{
Sean Shaheen \\ Editor-in-Chief, Journal of Photonics for Energy
}

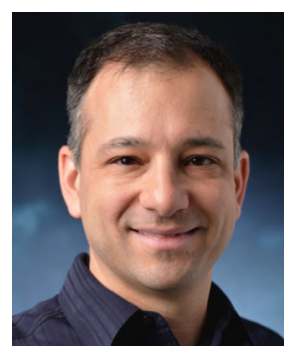

As reported by the EIA last year, ${ }^{1}$ solar photovoltaics (PV) are now the cheapest form of energy in most parts of the world. PV installations continue to accelerate with a record $134 \mathrm{GW}$ of capacity installed and $821 \mathrm{TWh}$ of energy generated in 2020. ${ }^{2}$ However, the Net Zero Emission by 2050 Scenario will require $7000 \mathrm{TWh}$ of generation by 2030 , a difficult task given that it will require an average growth rate of $24 \%$ per year for the remainder of this decade. ${ }^{2}$ The challenges to sustaining this level of growth may come from a number of areas, including the need for continued cost reductions in $\mathrm{PV}$ as measured by their levelized cost of electricity, ${ }^{3}$ development of a circular economy for PV materials and devices as they begin to age and need replaced, and build-out of the necessary electricity grid and storage capabilities on national and global scales.

Underlying these broader issues is of course the power conversion efficiency of the photovoltaic device itself. Although silicon PV technology has been able to drive the tremendous progress over the last decade with module efficiencies of $\sim 20 \%$, and it will continue to dominate the solar energy industry for the foreseeable future, there will be continued need to increase efficiencies to provide more power production per area from sunlight. It is a unique aspect of photovoltaic science that the efficiency limit with typical, single absorber, devices is seemingly low, $\sim 33 \%$ power conversion efficiency according to detailed balance of absorption and emission. ${ }^{4}$ That large-scale, commercial silicon PV can reach reasonably close to this value is a wonder of modern technology and industry. However, what can be non-intuitive to new students in the field is that this efficiency is sufficient for a photovoltaic panel to generate 100s of watts per square meter under 1-sun illumination, making solar energy viable as a large-scale and costeffective power source. For instance, $\sim 40 \%$ of the electricity needs of the U.S. could be met by roof-mounted solar panels of $\sim 16 \%$ efficiency. ${ }^{5}$ Globally, it has been estimated that there is $27 \mathrm{PWh} \mathrm{yr}^{-1}$ of rooftop electricity generation potential. ${ }^{6}$

Research on new photovoltaic concepts ${ }^{7}$ can open up pathways to the efficiency regime beyond the detailed-balance "barrier," enabling even more solar energy potential with less area, rooftop or land, required, and therefore less ecological and other impact. To that end, we invite submissions to our special section on Novel Photovoltaic Device Architectures, ${ }^{8}$ which will showcase new device architectures, materials, and photon management strategies to help propel the field into a new era of high-efficiency devices. Now is the time for the field to utilize advances in our understanding of thermodynamic principles of solar energy conversion, in the synthesis and characterization of nanoscale structures, and in the use of quickly developing computational and machine learning tools, to take the field of photovoltaics to the next level.

\section{References}

1. International Energy Agency, "World Energy Outlook 2020," IEA, Paris, 2020, https://www .iea.org/reports/world-energy-outlook-2020 (accessed December 2021).

2. International Energy Agency, "Solar PV," IEA, Paris, 2021, https://www.iea.org/reports/ solar-pv (accessed December 2021).

3. N. M. Haegel et al., "Terawatt-scale photovoltaics: transform global energy," Science 364(6443), 836-838 (2019).

4. H. J. Queisser, "Detailed balance: lifetimes and efficiencies," SPIE Proc. 6651, 665102 (2007).

(C) 2021 Society of Photo-Optical Instrumentation Engineers (SPIE) 
5. P. Gagnon et al., "Rooftop solar photovoltaic technical potential in the United States: a detailed assessment," Report NREL/TP-6A20-65298, 2016, https://www.nrel.gov/docs/ fy16osti/65298.pdf (accessed December 2021).

6. S. Joshi et al., "High resolution global spatiotemporal assessment of rooftop solar photovoltaics potential for renewable electricity generation," Nat. Commun. 12, 5738 (2021).

7. NSGE6, "Concepts to break the detailed-balance limit in photovoltaics," NGSE, https://www. ngse.info/ (accessed December 2021).

8. JPE, "Special section on novel photovoltaic device architectures," https://www.spie digitallibrary.org/journals/journal-of-photonics-for-energy/call-for-papers\#NovelPhotovoltaic DeviceArchitectures (accessed December 2021). 